\title{
AUTO-AVALIAÇÃO NA FUNDAÇÃO UNIVERSIDADE FEDERAL DO RIO GRANDE: METODOLOGIA DE AVALIAÇÃO
}

\author{
Tabajara Lucas de Almeida ${ }^{1}$ \\ SuZi SAMÁ PINTO ${ }^{2}$ \\ Humberto Camargo Piccoli ${ }^{3}$
}

Recebido em 10/05/07

Avaliado em: 24/08/07

1 Doutor em Engenharia de Produção, professor da FURG. E-mail: taba2508@gmail.com

2 Mestre em Engenharia Oceânica, professora da FURG. E-mail: suzisama@ furg.com.br

3 Doutor em Engenharia Mecânica, professor da FURG. E-mail: piccoli@dmc.furg.br

Resumo: O presente artigo propõe a utilização da Análise de Componentes Principais como metodologia quantitativa para auxiliar o processo de auto-avaliação das instituições de ensino superior. Esta metodologia foi aplicada na auto-avaliação da Fundação Universidade Federal do Rio Grande (FURG), em 2005, utilizando como instrumento de coleta de dados dois questionários de 39 questões, aplicados a estudantes e professores de graduação, contendo uma escala contínua de zero a dez. Os resultados para os estudantes mostraram a existência de sete componentes principais, onde a principal componente é o aspecto humano dos professores. Os resultados dos professores mostraram a existência de quatro componentes, sendo a principal aquela relacionada aos estudantes. A metodologia utilizada mostrou-se eficiente para alcançar os objetivos traçados pelos gestores da Instituição.

Palavras-chave: Auto-Avaliação, Ensino Superior, Análise de Componentes Principais.

Self-Evaluation during the foundation of the Federal University of Rio Grande: Evaluation Methodology

\begin{abstract}
The present article proposes the use of the Main Components Analysis as quantitative methodology to aid the process of self-evaluation in higher education institutions. This methodology was applied in the self-evaluation of the Fundação Universidade Federal do Rio Grande (FURG), in 2005, using as data collecting instrument two questionnaires with 39 questions, applied to undergraduate students and teachers, containing a continuous scale of zero to ten. The results for the students showed the existence of seven principal components, where the main component is the teachers' human aspect. The teachers' results showed the existence of four components, being the main one related to the students. The methodology used was shown efficient to reach the objectives drawn by the administrators of the Institution.
\end{abstract}

Key-words: Self-Evaluation; Higher Education; Main Component Analysis. 


\section{INTRODUÇÃO}

A auto-avaliação é um processo de auto-conhecimento que possibilita uma análise crítica da prática pedagógica e administrativa de uma instituição educacional. Permite identificar situações passíveis de mudança a fim de melhorar a qualidade dos diferentes processos relacionados à sua missão institucional.

Nesse sentido, pode-se entender a auto-avaliação como um processo de busca de subsídios para a melhoria da qualidade e eficiência da instituição, um instrumento de questionamento, um processo de reflexão e aperfeiçoamento em face dos objetivos ou missão desta no contexto social, econômico, político e cultural no qual está inserida.

A auto-avaliação é um processo coletivo, que não se pode resumir a iniciativas isoladas e pontuais. Ela deve ser um processo contínuo para que se pense de forma permanente e integrada a universidade que temos e a universidade que queremos, de forma a contribuir eficazmente para o cumprimento de sua missão institucional.

A ampla participação de toda a comunidade acadêmica é importante no processo avaliativo, seja no planejamento, no levantamento, na organização ou na análise dos dados. A participação e cooperação de todos, legitima o processo de avaliação, trazendo benefícios que contribuem para o aperfeiçoamento contínuo, para o conhecimento das limitações e potencialidades e de outras ações que impliquem em mudanças e melhorias que levem ao desenvolvimento da instituição.

Segundo Gasparetto (2006), é impensável conceber a avaliação dissociada da mudança, pois o mundo, a sociedade e a economia mudam num ritmo cada vez mais acelerado antecipando o processo de renovação do conhecimento e das tecnologias, o que impõe constantes desafios à universidade.

A avaliação deve ser transformadora. Não deve se satisfazer em levantar informações e analisá-las separadamente ou em categorias. Segundo Dias Sobrinho (2000, p. 107-108):

Embora seja mais fácil separar para conhecer, e ainda que seja necessário fragmentar no processo de conhecimento, na avaliação institucional é preciso ir além e buscar a significação de conjunto e em conjunto. [...] É insuficiente levantar os dados, torná-los visíveis, mais do que isso, é preciso selecioná-los pelos critérios de pertinência e relevância, interpretá-los, refletir sobre sua significação, buscando sempre a compreensão de conjunto. 
Somente assim a avaliação poderá contribuir para a obtenção de uma universidade voltada para o aperfeiçoamento do ensino, da extensão, da pesquisa e da gestão institucional, com a finalidade de torná-la relevante para a sociedade. Desta forma a avaliação estará atingindo sua função social. Para Belloni (2000, p. 56):

A função social da avaliação refere-se à possibilidade de levar uma instituição e o sistema a reexaminarem o seu funcionamento e o cumprimento de funções, mas, principalmente a reformularem a sua missão ou projeto institucional diante de novas características e demandas do desenvolvimento científico-tecnológico e sócio-cultural, levando à ampla transformação.

Cada instituição deve organizar e desenvolver seu processo de autoavaliação de acordo com suas especificidades e o contexto social, econômico, político e cultural no qual está inserida. A auto-avaliação deve ser encarada pela comunidade universitária como um processo rotineiro de reflexão e tomada de decisão.

A avaliação é um processo dinâmico que exige contínua reflexão sobre o processo avaliativo, pois além de ser afetada pelas especificidades dos estratos investigados ela é afetada pelas mudanças que o objeto de investigação sofre ao longo do tempo.

A implantação da auto-avaliação é um processo lento, permeado de tentativas e erros, que ao longo do tempo vão sendo superados. Apesar dos equívocos que inevitavelmente cometemos durante o processo de avaliação, não podemos negar a importância que ele possui no desenvolvimento e reconstrução da universidade. (COÊLHO, 2000).

Há uma grande discussão na literatura quanto à melhor metodologia a ser utilizada nos processos de avaliação. Acreditamos que os métodos qualitativos e quantitativos complementam-se e devem ser utilizados conjuntamente. Tal preceito é defendido por autores de referência, como Demo (1991) e Dias Sobrinho (1997). Estes autores defendem que a articulação entre os métodos qualitativos e quantitativos contribui para uma compreensão mais aprofundada do objeto de avaliação.

Os resultados obtidos na avaliação não chegam a ser conclusões definitivas ou certezas evidentes. No entanto, as informações obtidas na avaliação possibilitarão ações mais eficazes, quando baseadas em metodologias científicas consagradas. 
Conforme afirma Dias Sobrinho (1997, p. 72), "o essencial da avaliação [é]: construir de forma coerente um corpo de informações pertinentes, interpretá-las e atribuir-lhes juízos de valor que possam sustentar as articulações de transformação".

\section{CONTEXTUALIZANDO A FURG}

A Fundação Universidade Federal do Rio Grande (FURG) está localizada na cidade de Rio Grande no Estado do Rio Grande do Sul. Por estar situada numa região costeira, tem como principal campo de atuação o Ecossistema Costeiro que orienta suas atividades de ensino, pesquisa e extensão. No ensino, a Instituição atua nos três níveis: ensino médio e profissionalizante, graduação e pós-graduação.

A FURG tem aproximadamente 5.900 alunos, distribuídos em 34 cursos de graduação oferecidos em três campi nos turnos diurno e noturno.

Nos últimos anos a oferta de cursos de pós-graduação na FURG cresceu significativamente. Hoje são oferecidos 16 cursos lato sensu e 14 cursos stricto sensu. A partir de 2007 a FURG começará a oferecer cursos na modalidade à distância acompanhando as mudanças que a sociedade contemporânea exige na estrutura universitária.

Atualmente está sendo feita uma revisão nos seus estatutos tanto do ponto de vista político quanto organizacional, a fim de adequá-los à nova realidade institucional. Nesse sentido, a auto-avaliação é um instrumento fundamental, organizador da coerência do conjunto das ações na reestruturação da Instituição.

\section{A AUTO-AVALIAÇÃO NA FURG}

A experiência da auto-avaliação na FURG começou em 1993, dentro do Programa de Avaliação Institucional das Universidades Brasileiras (PAIUB), em cujo âmbito foi desenvolvido o projeto "Avaliação dos cursos de graduação da FURG”. A partir de 1994 foi implementada a avaliação do desempenho acadêmico de docentes para fins de progressão funcional que, em 1999, incorporou a "Avaliação dos Docentes pelos Discentes" como um de seus instrumentos.

As implementações do Exame Nacional de Curso (Provão) e da Avaliação das Condições de Oferta em 1998 alteraram a postura das unidades acadêmicas fazendo com que as mesmas se preocupassem em melhorar seu desempenho e corrigir suas deficiências.

Em 2004, a criação do SINAES fez com que a FURG assumisse a auto-avaliação como processo permanente através da constituição da Co- 
missão Própria de Avaliação. Foi instituída a Secretaria de Avaliação Institucional (SAI), para dar suporte às ações de avaliação. Seguiu-se uma revisão do Projeto de Auto-Avaliação Institucional quando foi adotada a opção por realizar, inicialmente a auto-avaliação das atividades de ensino de graduação.

Além da avaliação dos cursos de graduação, de que trata o presente artigo, estão sendo realizadas avaliações na gestão, pesquisa, extensão, pós-graduação e no ensino médio e profissionalizante.

Ao final do processo avaliativo, considerando as várias etapas de avaliação acima citadas, a FURG terá uma visão completa e única de seus critérios de pertinência e relevância, atingindo a compreensão de conjunto.

\section{METODOLOGIA}

$\mathrm{O}$ instrumento de pesquisa aplicado neste estudo foi baseado no trabalho desenvolvido por Almeida et al., (2000) no curso de Engenharia Civil da FURG. Neste trabalho Almeida utilizou a metodologia de grupo focal para elaborar os questionários utilizados na investigação do pensamento dos estudantes e dos professores, quanto a sua satisfação com os diversos aspectos do curso.

Devido às diversidades entre os cursos de graduação oferecidos pela FURG, inicialmente, a Comissão Própria de Avaliação (CPA) adaptou as questões dos questionários desenvolvidos por Almeida, de forma que estes pudessem ser aplicados a todos os estudantes e professores da instituição.

A seguir, foi aplicada uma amostra-piloto do questionário adaptado, para verificar a confiabilidade do mesmo e, ainda, se as questões foram elaboradas de forma apropriada. O coeficiente de confiabilidade mede a fidedignidade e coerência das questões formuladas. Há várias maneiras de se estimar o coeficiente de confiabilidade de um questionário, neste trabalho ele é estimado através do coeficiente Alfa de Cronbach. Segundo Silveira (1993), o mínimo aceitável para o Alfa de Cronbach depende da utilização que se fará com os escores gerados pelo instrumento. Coeficientes da ordem de 0,70 são aceitáveis quando se deseja comparar grupos em que não há intenção de classificar os respondentes (como ocorre em concurso vestibular). Quando este coeficiente é próximo de 1 (um), significa que o instrumento é capaz de detectar muito bem as diferenças entre os respondentes no grupo investigado. O resultado de 0,92 para o coeficiente do questionário deste estudo, portanto, indica um nível muito bom de confiabilidade. 
$\mathrm{Na}$ análise dos dados, foi utilizada a Análise de Componentes Principais (ACP). Esta técnica multivariada permite identificar padrões ou relações subjacentes entre as várias questões de um instrumento e determinar se a informação pode ser condensada ou resumida em um conjunto menor de fatores ou componentes. Portanto, a aplicação da ACP resulta em um novo conjunto de variáveis denominadas componentes principais, onde cada uma representa um conjunto de questões inter-relacionadas que identificam os padrões existentes nos dados.

Para interpretar os padrões existentes nos dados, ou seja, as componentes principais, deve-se observar o percentual de variação que cada componente explica. A componente principal que concentra a maior parte da variação total encontrada nos dados originais é a mais importante. A segunda componente principal mais importante é aquela que explica a maior variação restante, que não foi explicada pela primeira componente principal e assim sucessivamente. É importante ressaltar que a interpretação das componentes principais possui um grau de subjetividade, assim podendo variar de pesquisador para pesquisador.

Para melhorar a interpretação das componentes foi aplicada a rotação Varimax, que possibilita reduzir as ambigüidades que freqüentemente acompanham uma solução sem rotação. Uma descrição mais detalhada sobre a análise de componentes principais é apresentada em HAIR et al. (1998), Green (1978) e Pinto (2001).

\section{ANÁLISE E DISCUSSÃO DOS RESULTADOS}

Foram aplicados dois questionários: um aos estudantes e outro aos professores.

Os questionários consistem de 39 questões em quatro blocos, onde cada um possui um conjunto de questões relativas a diferentes temas. No questionário aplicado aos estudantes os temas são: professores, disciplinas, infra-estrutura e estudantes. No questionário aplicado aos professores os temas são: estudantes e turmas, infra-estrutura, prática docente e curso. Cinco questões são de fechamento de bloco, as quais não foram levadas em consideração nessa análise.

Cada respondente atribuiu uma nota de zero a dez de acordo com a sua concordância na afirmação de cada questão.

Dos 5.937 estudantes distribuídos nos três campi da universidade, 3.178 responderam voluntariamente o questionário, o que representa 53,5\% do total de alunos matriculados nos 34 cursos de graduação da FURG. 
A decisão sobre o número de componentes principais a serem retidas na análise foi tomada com base no teste Scree e no critério de autovalores maiores do que um (tabela 1).

$\mathrm{Na}$ análise do questionário aplicado aos estudantes, foram retidas sete componentes principais (CP) que juntas explicam $62 \%$ da variação total dos dados, o que pode ser considerado aceitável para investigações na área de ciências humanas (HAIR et al, 1998).

Este resultado indica que, na concepção dos estudantes, a satisfação com os cursos de graduação da FURG é multidimensional.

Tabela 1: Autovalores do questionário aplicado aos discentes

\begin{tabular}{|c|c|c|c|}
\hline $\mathrm{CP}$ & Autovalor & \% Total & $\%$ Acumulada \\
\hline 1 & 4,90 & $14,4 \%$ & $14,4 \%$ \\
\hline 2 & 4,37 & $12,8 \%$ & $27,2 \%$ \\
\hline 3 & 3,42 & $10,1 \%$ & $37,3 \%$ \\
\hline 4 & 2,53 & $7,40 \%$ & $44,7 \%$ \\
\hline 5 & 2,44 & $7,20 \%$ & $51,9 \%$ \\
\hline 6 & 1,73 & $5,10 \%$ & $57,0 \%$ \\
\hline 7 & 1,70 & $5,00 \%$ & $62,0 \%$ \\
\hline
\end{tabular}

Foram consideradas significativas as componentes com cargas fatoriais iguais ou superiores a 0,50. A carga fatorial indica a correlação de uma questão com a componente principal em apreço. Quanto mais próxima de 1 (um) mais forte é a correlação e quanto mais próxima de zero mais fraca. Uma questão com forte correlação em uma CP caracteriza o sentido subjacente desta componente.

Nas tabelas a seguir, às questões do questionário são apresentadas de acordo com a sua carga em cada componente, em ordem decrescente.

As questões que compõem a primeira $\mathrm{CP}$, tabela 2, representam um fator subjacente que pode ser interpretado como relativo ao aspecto humano dos professores da FURG. Esta componente explica 14,4\% da variação total dos dados. O resultado indica que o aspecto humano dos professores é o fator mais importante na satisfação do estudante com o seu curso.

A média aritmética de cada uma das questões que compõem esta $\mathrm{CP}$ também é apresentada na tabela 2. Dado que a cultura institucional consagrou, na nota final do estudante, o valor 7,0 para aprovação por média nas disciplinas e o valor 5,0 como mínimo de aprovação, este critério foi ado- 
tado na análise da satisfação de estudantes e professores com a Instituição. Dentre as afirmações que compõem esta $\mathrm{CP}$, a questão: "os professores dispensam aos estudantes tratamento cordial e respeitoso" é a que apresenta a maior média $(7,8)$. Isto indica que esta questão está sendo atendida pelos professores. Já a afirmação: “os professores possuem habilidade em despertar o interesse dos estudantes pela disciplina" é o item que apresenta a menor média $(6,1)$, que não pode ser considerada uma média satisfatória. Portanto, podemos concluir que esta questão é importante, por pertencer a CP1, mas não está sendo atendida pelos professores, pois sua média não é satisfatória.

Além desta questão merecem atenção as seguintes afirmativas: "os professores têm interesse pelo aprendizado dos estudantes" e "os professores promovem ações que ajudam na formação dos estudantes (atitude, normas e valores)", ambas com médias abaixo de 7,0.

Tabela 2: Resultado da CP 1= Aspecto Humano dos Professores

\begin{tabular}{|c|l|c|c|}
\hline № & \multicolumn{1}{|c|}{ Questões } & Carga & Média \\
\hline 07 & Possuem disposição ao diálogo, respeitando pontos de vista contrários. & 0,74 & 7,1 \\
\hline 06 & Têm interesse pelo aprendizado dos estudantes. & 0,68 & 6,8 \\
\hline 05 & Demonstram satisfação em ensinar. & 0,68 & 7,1 \\
\hline 08 & $\begin{array}{l}\text { Apresentam disposição para atender aos estudantes fora dos horários das } \\
\text { aulas. }\end{array}$ & 0,66 & 7,7 \\
\hline 09 & Dispensam aos estudantes tratamento cordial e respeitoso. & 0,65 & 7,8 \\
\hline 11 & Elaboram avaliações compatíveis com o conteúdo desenvolvido. & 0,62 & 7,3 \\
\hline 04 & Apresentam clareza na exposição dos temas abordados. & 0,61 & 7,0 \\
\hline 12 & $\begin{array}{l}\text { Promovem ações que ajudam na formação dos estudantes (atitude, } \\
\text { normas e valores). }\end{array}$ & 0,54 & 6,8 \\
\hline 03 & $\begin{array}{l}\text { Possuem habilidade em despertar o interesse dos estudantes pela } \\
\text { disciplina. }\end{array}$ & 0,50 & 6,1 \\
\hline & Porcentagem Total de Variação Explicada = 14,4\% & \\
\hline
\end{tabular}

A segunda CP, tabela 3, está relacionada com a qualidade das disciplinas. Esta componente explica 12,8\% da variação total dos dados. A questão que trata da integração entre a teoria e prática é a que apresenta a maior correlação $(0,82)$ com esta $C P$. Dado que a sua média está abaixo de 7,0, deverá haver preocupação por parte dos gestores da FURG em desenvolver planos de ação que incentivem os professores a demonstrar a relação entre a teoria e a prática, permitindo a compreensão de sua relevância social por parte dos estudantes. 
Pelas médias obtidas em todas as questões desta $\mathrm{CP}$ pode-se verificar que a qualidade das disciplinas é um fator que pode ser melhorado.

Tabela 3 - Resultado da CP 2 = Qualidade das Disciplinas

\begin{tabular}{|c|l|c|c|}
\hline \multicolumn{1}{|c|}{ Q № } & \multicolumn{1}{|c|}{ Cuestões } & Carga & Média \\
\hline 17 & Há integração entre teoria e prática. & 0,82 & 6,4 \\
\hline 02 & Relacionam o conteúdo teórico apresentado com a prática. & 0,74 & 6,7 \\
\hline 18 & A relação entre a carga horária teórica e prática é adequada. & 0,73 & 6,0 \\
\hline 16 & Há clareza quanto à utilidade das disciplinas para a capacitação profissional. & 0,66 & 6,9 \\
\hline 03 & Possuem habilidade em despertar o interesse dos estudantes pela disciplina. & 0,59 & 6,1 \\
\hline 19 & Há integração entre as disciplinas do curso. & 0,55 & 6,3 \\
\hline & Porcentagem Total de Variação Explicada $=\mathbf{1 2 , 8} \%$ & & \\
\hline
\end{tabular}

A terceira CP, tabela 4 , explica $10,1 \%$ da variação total dos dados e refere-se à infra-estrutura de apoio às disciplinas. Pelas médias obtidas nas questões, apenas a questão referente à conservação e limpeza das dependências em geral está sendo atendida satisfatoriamente.

Tabela 4 - Resultado da CP 3 = Infra-estrutura das disciplinas

\begin{tabular}{|c|l|c|c|}
\hline № & \multicolumn{1}{|c|}{ Questões } & Carga & Média \\
\hline 25 & As salas de aula são salubres (boa iluminação, conforto térmico e acústico). & 0,7882 & 6,9 \\
\hline 27 & $\begin{array}{l}\text { As dependências em geral apresentam níveis adequados de limpeza e } \\
\text { conservação. }\end{array}$ & 0,7854 & 7,9 \\
\hline 26 & As cadeiras das salas de aula são confortáveis. & 0,72 & 5,4 \\
\hline 28 & Os equipamentos utilizados são compatíveis com as necessidades do curso. & 0,66 & 6,5 \\
\hline 29 & Os equipamentos disponíveis são em quantidade adequada à demanda. & 0,60 & 5,6 \\
\hline & Porcentagem Total de Variação Explicada = 10,1\% & \\
\hline
\end{tabular}

A quarta CP, tabela 5, está relacionada aos estudantes e explica $7,4 \%$ da variação total dos dados. A questão que apresenta a maior carga com esta CP é a que afirma que o nível de preparo dos colegas da turma é adequado às necessidades do curso. Dentro da concepção dos alunos o preparo dos colegas é considerado satisfatório (média=7,0). Quanto aos estudantes verifica-se que, na opinião destes, eles não utilizam os canais institucionais para apresentação de suas demandas e sugestões (média=5,8). 
Tabela 5 - Resultado da CP 4 = Estudantes

\begin{tabular}{|c|l|c|c|}
\hline № & \multicolumn{1}{|c|}{ Questões } & Carga & Média \\
\hline 36 & $\begin{array}{l}\text { O nível de preparo dos colegas da turma é adequado às } \\
\text { necessidades do curso. }\end{array}$ & 0,80 & 7,0 \\
\hline 35 & O relacionamento entre os colegas é bom. & 0,75 & 7,7 \\
\hline 34 & $\begin{array}{l}\text { Os estudantes apresentam interesse pelo processo ensino } \\
\text { aprendizagem. }\end{array}$ & 0,73 & 7,0 \\
\hline 37 & $\begin{array}{l}\text { Os estudantes utilizam os canais institucionais para apresentação de } \\
\text { suas demandas e gestões. }\end{array}$ & 0,59 & 5,8 \\
\hline & Porcentagem Total de Variação Explicada $=7,4 \%$ & & \\
\hline
\end{tabular}

A quinta $\mathrm{CP}$, tabela 6 , refere-se à infra-estrutura da biblioteca e explica 7,2\% da variação total dos dados. As maiores cargas nesta CP são referentes às questões que verificam se a quantidade de livros e periódicos disponíveis na biblioteca atendem as necessidades das disciplinas. Como pode ser observado pelas médias obtidas nestas duas questões (média=5,8) elas não estão sendo bem atendidas.

Tabela 6 - Resultado da CP 5 = Infra-estrutura de Biblioteca

\begin{tabular}{|l|l|c|c|}
\hline № & \multicolumn{1}{|c|}{ Questões } & Carga & Média \\
\hline 22 & Os livros disponíveis na biblioteca atendem às necessidades das disciplinas & 0,85 & 5,8 \\
\hline 23 & $\begin{array}{l}\text { Os periódicos existentes na biblioteca atendem às necessidades das } \\
\text { disciplinas }\end{array}$ & 0,83 & 5,8 \\
\hline 24 & A biblioteca conta com espaço físico adequado para estudo e consulta. & 0,58 & 7,7 \\
\hline & Porcentagem Total de Variação Explicada $=\mathbf{7 , 2} \%$ & & \\
\hline
\end{tabular}

A sexta CP, tabela 7, retrata o aspecto ético dos professores e explica $5,1 \%$ da variação total dos dados. Analisando as médias podemos verificar que as questões que tratam da assiduidade e pontualidade dos professores são consideradas satisfatórias pelos alunos.

Tabela 7 - Resultado da CP 6 = Aspecto Ético dos Professores

\begin{tabular}{|c|l|c|c|}
\hline № & \multicolumn{1}{|c|}{ Questões } & Carga & Média \\
\hline 13 & São assíduos (não faltam às aulas). & 0,8 & 8,1 \\
\hline 14 & Cumprem os horários de início e término das aulas. & 0,79 & 7,6 \\
\hline & Porcentagem Total de Variação Explicada $\mathbf{= 5 , 1 \%}$ & \multicolumn{2}{|l}{} \\
\hline
\end{tabular}


A sétima $\mathrm{CP}$, tabela 8 , está relacionada à Infra-estrutura de apoio e explica 5\% da variação total dos dados. Pelas médias obtidas em todas as questões desta CP pode-se verificar que a infra-estrutura de apoio é um fator que não está sendo atendido. A questão referente aos horários dos ônibus é que apresenta a maior carga nesta $\mathrm{CP}$ e a menor média (média=4,8) em todo o questionário. Esta questão pode ser interpretada como importante para o fator, porém bastante insatisfatória.

Tabela 8 - Resultado da CP 7 = Infra-estrutura de Apoio

\begin{tabular}{|l|l|c|c|}
\hline № & \multicolumn{1}{|c|}{ Questões } & Carga & Média \\
\hline 32 & Os horários dos ônibus atendem às necessidades dos estudantes. & 0,71 & 4,8 \\
\hline 30 & A alimentação oferecida nas lancherias e restaurantes é de boa qualidade. & 0,55 & 6,6 \\
\hline 31 & $\begin{array}{l}\text { As condições de segurança no campus (vias de acesso, salas de aula, } \\
\text { laboratórios, gabinetes etc.) são satisfatórias. }\end{array}$ & 0,53 & 6,9 \\
\hline & Porcentagem Total de Variação Explicada $\mathbf{= 5 , 0 \%}$ & & \\
\hline
\end{tabular}

O questionário aplicado aos professores foi separado em quatro blocos de questões referentes ao estudante, ao curso, a infra-estrutura e a prática docente. Neste caso, como alguns professores atuam em mais de um curso não foi possível obter-se o percentual de retorno dos questionários dos docentes. A presente análise foi realizada com os 425 questionários entregues pelos docentes.

Foram retidas quatro componentes principais $(\mathrm{CP})$ que juntas explicam $58 \%$ da variação total dos dados. Sendo que a CP1 explica $22 \%$ desta variação como pode ser observado na tabela 9.

Tabela 9 : Autovalores do questionário aplicado aos docentes

\begin{tabular}{|c|c|c|c|}
\hline CP & Autovalor & $\%$ Total & \% Acumulada \\
\hline 1 & 7,71 & $22 \%$ & $22 \%$ \\
\hline 2 & 4,72 & $13 \%$ & $35 \%$ \\
\hline 3 & 4,10 & $12 \%$ & $47 \%$ \\
\hline 4 & 3,98 & $11 \%$ & $58 \%$ \\
\hline
\end{tabular}

As questões que compõem a primeira $\mathrm{CP}$, tabela 10, representam um fator subjacente que pode ser interpretado como relativo aos estudantes. Esta componente explica $22 \%$ da variação total dos dados. O interesse dos alunos pelas aulas e disciplinas do curso, o relaciona- 
mento professor-turma/aluno e o comportamento e pontualidade dos estudantes nas aulas são as questões que apresentam as maiores cargas na primeira CP. Dentre estas questões a pontualidade dos estudantes não é considerada satisfatória. Assim como, as questões referentes à iniciativa na resolução de problemas, consulta à bibliografia e o preparo dos alunos para compreensão das informações e conhecimentos trabalhados no curso.

Tabela 10: Resultados da CP 1 = Estudante

\begin{tabular}{|c|l|c|c|}
\hline № & \multicolumn{1}{|c|}{ Questões } & Carga & Média \\
\hline 03 & Os estudantes são interessados nas aulas ministradas. & 0,83 & 7,4 \\
\hline 02 & Os estudantes permanecem na sala durante a aula. & 0,752 & 7,6 \\
\hline 04 & Há interesse dos estudantes pelas disciplinas do curso. & 0,748 & 7,4 \\
\hline 12 & A relação professor-turma é positiva. & 0,74 & 8,5 \\
\hline 09 & Os estudantes têm comportamento adequado em sala de aula. & 0,73 & 7,7 \\
\hline 11 & A relação professor-aluno é positiva. & 0,71 & 8,6 \\
\hline 01 & Os estudantes são pontuais. & 0,70 & 6,6 \\
\hline 05 & Os estudantes demonstram iniciativa para a resolução de problemas. & 0,68 & 6,6 \\
\hline 10 & O relacionamento entre os estudantes é positivo. & 0,67 & 8,3 \\
\hline 24 & Consigo despertar o interesse dos estudantes pela disciplina. & 0,66 & 7,9 \\
\hline 06 & Os estudantes demonstram estar preparados para compreender as informações & 0,64 & 6,6 \\
\hline 13 & Os estudantes têm vocação para o curso. & 0,62 & 7,3 \\
\hline 08 & Os estudantes consultam a bibliografia indicada . & 0,59 & 6,4 \\
\hline 07 & Os estudantes manifestam interesse por aulas práticas. & 0,57 & 7,6 \\
\hline & Porcentagem Total de Variação Explicada = 22\% & \\
\hline
\end{tabular}

A segunda $\mathrm{CP}$, tabela 11 , explica $13 \%$ da variação dos dados e refere-se ao curso. As questões com maior carga nesta CP são: o curso forma bons profissionais e o curso forma profissionais generalistas com bom embasamento científico. A oferta de projetos de iniciação cientifica não é satisfatória (média $=6,5$ ) na opinião dos professores.

Tabela 11 - Resultados da CP 2 = Curso

\begin{tabular}{|c|l|c|c|}
\hline № & \multicolumn{1}{|c|}{ Questões } & Carga & Média \\
\hline 36 & O Curso forma bons profissionais. & 0,824 & 7,8 \\
\hline 35 & $\begin{array}{l}\text { O Curso forma profissionais generalistas com bom embasamento } \\
\text { científico. }\end{array}$ & 0,823 & 7,6 \\
\hline 33 & O Curso propicia boa formação teórica. & 0,76 & 8,0 \\
\hline 34 & O Curso propicia boa formação prática. & 0,73 & 7,4 \\
\hline 38 & $\begin{array}{l}\text { Os estudantes demonstram interesse em participar de projetos de } \\
\text { pesquisa e extensão. }\end{array}$ & 0,64 & 7,5 \\
\hline 37 & Há oferta suficiente de projetos de iniciação científica. & 0,63 & 6,5 \\
\hline & Porcentagem Total de Variação Explicada $\mathbf{1 3} \%$ & \multicolumn{2}{|l}{} \\
\hline
\end{tabular}


As questões que compõem a terceira $\mathrm{CP}$, tabela 12 , representam a infra-estrutura. A única questão considerada satisfatória para os professores é em relação à limpeza e conservação das dependências em geral.

Tabela 12 - Resultados da CP 3 = Infra-estrutura

\begin{tabular}{|c|l|c|c|}
\hline № & \multicolumn{1}{|c|}{ Questões } & Carga & Média \\
\hline 18 & O acervo bibliográfico disponível aos estudantes é suficiente. & 0,77 & 5,3 \\
\hline 16 & $\begin{array}{l}\text { Os equipamentos de apoio didático-pedagógicos disponíveis para uso } \\
\text { em salas de aula são adequados (quadros, multimídia, retro-projetores e } \\
\text { outros). }\end{array}$ & 0,74 & 6,3 \\
\hline 19 & O acervo bibliográfico é atualizado. & 0,73 & 5,3 \\
\hline 17 & $\begin{array}{l}\text { Os equipamentos dos laboratórios são compatíveis com as } \\
\text { necessidades do curso. }\end{array}$ & 0,72 & 5,9 \\
\hline 15 & $\begin{array}{l}\text { As salas de aula são adequadas (cadeiras ergonômicas, boa iluminação, } \\
\text { conforto térmico e acústico). }\end{array}$ & 0,67 & 6,0 \\
\hline 20 & $\begin{array}{l}\text { As salas de permanência são adequadas. } \\
21\end{array}$ & $\begin{array}{l}\text { As dependências em geral apresentam níveis adequados de limpeza e } \\
\text { conservação. }\end{array}$ & 0,65 \\
\hline & Porcentagem Total de Variação Explicada = 12\% & 6,5 \\
\hline
\end{tabular}

As questões que compõem a quarta $\mathrm{CP}$, tabela 13 , representam um fator latente que se refere à prática docente. Esta $\mathrm{CP}$ explica $11 \%$ da variação dos dados. Conforme as médias das questões que compõem esta CP, pode-se verificar que para os professores sua prática docente é plenamente satisfatória.

\section{Tabela 13 - Resultados da CP 4 = Prática Docente}

\begin{tabular}{|c|l|c|c|}
\hline № & \multicolumn{1}{|c|}{ Questões } & Carga & Média \\
\hline 28 & Respeito opiniões dos estudantes. & 0,79 & 9,2 \\
\hline 27 & Trato os estudantes de forma equânime. & 0,76 & 9,0 \\
\hline 26 & Trato gentilmente os estudantes. & 0,71 & 9,0 \\
\hline 29 & Estabeleço prazos adequados para entrega de trabalhos e projetos. & 0,68 & 9,2 \\
\hline 31 & $\begin{array}{l}\text { Incorporo os conhecimentos obtidos na pesquisa, extensão e exercício } \\
\text { profissional a minha prática pedagógica. }\end{array}$ & 0,54 & 9,0 \\
\hline 23 & Tenho satisfação em ensinar. & 0,50 & 9,0 \\
\hline & Porcentagem Total de Variação Explicada =11\% & \multicolumn{2}{l|}{} \\
\hline
\end{tabular}




\section{Conclusões}

Analisando os resultados obtidos podemos verificar que, para os estudantes da FURG, os cursos de graduação apresentam sete dimensões de satisfação, que juntas explicam $62 \%$ da variação total dos dados. As sete dimensões por ordem de importância são: aspecto humano dos professores, qualidade das disciplinas, infra-estrutura das disciplinas, estudantes, infra-estrutura de biblioteca, aspecto ético dos professores e infraestrutura de apoio.

$\mathrm{O}$ aspecto humano dos professores é o fator mais importante na satisfação do aluno com o curso. A integração entre teoria e prática e a integração entre as disciplinas do curso merecem maior atenção dos gestores e dos professores. Ações neste sentido poderão melhorar a satisfação dos estudantes com os cursos, no tocante às questões da primeira $\mathrm{CP}$ que foram consideradas insatisfatórias, tais como o interesse dos professores pelo aprendizado dos estudantes e a habilidade dos professores em despertar o interesse deles pela disciplina. As salas de aula, as cadeiras, a quantidade e compatibilidade dos equipamentos utilizados no curso, os livros e periódicos disponíveis na biblioteca, a alimentação oferecida e a segurança dos campi merecem mais atenção por parte dos gestores da universidade. Ações junto às autoridades competentes para solucionar o problema no serviço de transporte coletivo urbano também devem ser consideradas.

$\mathrm{Na}$ análise dos questionários aplicados aos professores foram selecionadas quatro $\mathrm{CP}$ que juntas explicam $58 \%$ da variação total dos dados. As dimensões por ordem de importância são: estudantes, curso, infra-estrutura e prática docente.

O interesse dos alunos pelas aulas e disciplinas do curso, o relacionamento professor-turma/aluno e o comportamento e pontualidade dos estudantes nas aulas são as questões que apresentam as maiores cargas na primeira CP. Dentre estas questões a pontualidade dos estudantes não é considerada satisfatória. Assim como, as questões referentes à iniciativa na resolução de problemas, consulta à bibliografia e o preparo dos alunos para compreensão das informações e conhecimentos trabalhados no curso.

Quanto ao Curso, os professores vêem apenas a necessidade de aumentar a oferta de projetos de iniciação cientifica.

Quanto à infra-estrutura física, obteve-se resultados semelhantes ao encontrado entre os estudantes, ficando evidente a necessidade de melhores investimentos no acervo bibliográfico, nos equipamentos de apoio 
didático-pedagógicos, nos equipamentos dos laboratórios, na adequação das salas de aula e das salas de permanência dos professores. A prática docente na visão dos estudantes é o fator mais importante, no entanto, para os professores este fator ficou na última componente, o que demonstra conflito de opiniões que deve ser analisado. Os professores estão plenamente satisfeitos com sua prática docente, sendo que as questões com maior carga, nesta última $\mathrm{CP}$, referem-se ao tratamento cordial, respeitoso e equânime dispensado aos alunos pelos professores.

A análise aqui apresentada refere-se à visão global com a satisfação de um sujeito coletivo, estudante de graduação da FURG, independente do Curso e de outro sujeito coletivo, professor da FURG, independente da área de atuação. Análises específicas por curso de graduação, utilizando a mesma metodologia aqui exposta, estão sendo devidamente elaboradas.

A metodologia aplicada alcançou resultados satisfatórios do ponto de vista técnico e considerando o grau de subjetividade intrínseco à análise, também foi satisfatória do ponto de vista da boa receptividade obtida junto aos gestores, para quem os resultados foram apresentados.

\section{REFERÊNCIAS}

ALMEIDA, T. L. et al. Medida de satisfação dos estudantes de Engenharia Civil da FURG-Ano 2000. In: CONGRESSO BRASILEIRO DE ENSINO DE ENGENHARIA, 29, 2001, Porto Alegre. Anais ... Porto Alegre: EDIPUCRS, 2001. 1 Cd-Rom.

BELLONI, Isaura. A Função Social da Avaliação Institucional. In: DIAS SOBRINHO, José; RISTOFF, Dilvo I. Universidade desconstruída: avaliação institucional e resistência. Florianópolis: Insular, 2000.

COÊLHO, Ildeu Moreira. Avaliação Institucional na Universidade Pública. In: DIAS SOBRINHO, José; RISTOFF. Dilvo I. Universidade desconstruída: avaliação institucional e resistência. Florianópolis: Insular, 2000 .

DEMO, Pedro. Avaliação qualitativa. 3. ed. São Paulo: Cortez, 1991.

DIAS SOBRINHO, José. Avaliação Quantitativa e Avaliação Qualitativa: Interações e Ênfases. In: SGUISSARDI, V. Avaliação universitária em questão: reformas do estado e da educação superior. (Org.). Campinas: Autores Associados, 1997.

Avaliação institucional na perspectiva da integração. In: DIAS SOBRINHO, José; RISTOFF, Dilvo I. Universidade desconstruída: avaliação institucional e resistência. Florianópolis: Insular, 2000. 
GASPARETTO, Agenor. Avaliação institucional: processo doloroso de mudança: a experiência da UESC. Ilhéus, Bahia. Disponível em <http:// www.socio-estatistica.com.br/avalia.htm> Acesso 20 fev. de 2006.

GREEN, P. E. Analyzing multivariate data. Philadelphia: Dryden Press, 1978.

HAIR, J.F. et al.; Multivariate data analysis. 5. ed. New Jersey: Prentice Hall, 1998.

PINTO, Suzi Samá. Análise de componente principais de observações meteorológicas de superfície em Rio Grande, RS, no período de 1991 a 2000. Dissertação (Mestrado em Engenharia Oceânica) - Fundação Universidade Federal do Rio Grande, Rio Grande, 2001.

SILVEIRA, Fernando Lang. Validação de testes de papel e lápis. Porto Alegre: PUCRS, 1993 